the lithosphere at this depth, even at ro miles, we have as yet no positive knowledge, but the distribution of igneous rocks at the surface of the earth, and a comparison of oceanic and continental regions, give us some important facts to guide our reasoning on this matter. We are probably not far from the truth if we assume that the granitic portion of the lithosphere is largely restricted to the continental regions of the earth, and its thickness may not exceed an average of about 5 miles. If so, assuming this granite layer in continental regions to contain on an average 70 per cent. of silica, and assuming that it is underlain to a depth of ro miles from the surface by basalt containing on an average 48 per cent. of silica, this would give us a silica percentage of about 59 for the average igneous rock of the lithosphere in continental regions down to a depth of ro miles, which is in agreement with the average of the igneous rock of the "crust" as estimated by Clarke and Washington.

It should be noted that this takes no account of the "crust" of the oceanic regions, which is probably in large part basaltic. We may for the purpose of this argument assume that the granite shell of continental regions covers half the earth. This is an extravagant assumption, but as it doubtless errs substantially in exaggerating the acidity of the "crust," the error is on the right side so far as the present argument is concerned. If we further assume the sub-oceanic "crust" down to a depth of ro miles to be basaltic, and to contain on an average 48 per cent. of silica, this would give us an average igneous rock containing about $53 \frac{1}{2}$ per cent. of silica for the outer ro miles of the lithosphere all round the earth.

Extending our considerations to a depth of 20 miles, there can be little doubt that we should regard the deeper ro miles as on the whole more basic than the basaltic material of the outer ro miles, and it is reasonable to assume that this deeper layer of basalt does not contain on the average more than 46 per cent. of silica. If we make this assumption, then the average rock of the earth's " crust" as a whole down to a depth of 20 miles would contain not more than about $5 \circ$ per cent. of silica.

Comparing these with the figures given above by Clarke and Washington, the inference we draw is that they have probably much understated the basicity of the earth's " crust." Their average down to a depth of Io miles is, as we have seen, only acceptable for continental regions, and cannot be admitted for the earth as a whole. Still less can their average for the lithosphere down to a depth of 20 miles be admitted, for, as we have seen, there is good reason for believing that the average rock down to this depth probably corresponds to a gabbro, containing about 50 per cent. of silica, rather than, as they infer, to a granodiorite containing 59 per cent. of silica.

This question of the average composition of the earth's "crust" has important bearings on many scientific and economic problems. It is quite commonly assumed that the average igneous rock is intermediate in composition, and that granitic and basaltic eruptives are products of differentiation derived from intermediate magmas. It seems highly probable, however, that the average igneous rock of the earth's crust is basic ; and although differentiation does undoubtedly play an important part in the formation of igneous rocks, the claim that granites and basalts are in general differentiates from magmas of intermediate composition has no adequate foundation in the facts known to us concerning the petrology of the earth.

\title{
Centenary of the Death of William Herschel.
}

$\mathrm{O}^{\mathrm{N}}$ August 25, 1822-a hundred years agoWilliam Herschel died at Slough, aged eightythree years and nine months. His scientific activity had continued almost to the end of his long life. His last published paper was read before the Royal Astronomical Society (of which he was the first President) in June I82r. It is the only one of his seventy memoirs which was not published in the Philosophical Transactions, of the yearly volumes of which for the years I780 to I8I8 inclusive only those for 1813 and 1816 contain nothing by him, while not a few volumes include several papers from his hand. Even in the last year of his life, when his son, under his continual guidance, made and figured the 183 -inch mirror, which was afterwards used by Sir John Herschel at Slough and at the Cape, it is recorded that " the interest he took in this work and the clearness and precision of his directions showed a mind unbroken by age and still capable of turning all the resources of former experience to the best account."

When Herschel, on March I, I774, began to keep a record of what he saw in the heavens with telescopes made by himself, it was natural that he should for some years show no decided preference for any particular branch of astronomy. At first he paid some attention to the planets, and determined the rotation-periods of Jupiter and Mars. But it did not escape his clear perception very long that what was urgently required at that time was a systematic study of the vast number of celestial bodies outside the solar system. If Herschel had not early grasped this fact, and persevered all the rest of his life in his devotion to sidereal astronomy, he would never have become a great astronomer, but would merely, like his contemporary, Schröter, have been known as an indefatigable observer who occasionally did some good work. But on his way from the solar system out into space beyond it Herschel found a new planet (Uranus), about twice as far from the sun as what had up to then been considered the outermost planet. This was not a lucky accident, but a discovery which was bound to be made sooner or later by an observer who searched the heavens as systematically as he did. It was the first time since the prehistoric ages that a new planet was discovered. Herschel afterwards found two satellites of Uranus and two of Saturn, but his principal work was always on subjects connected with sidereal astronomy.

"A knowledge of the construction of the heavens has always been the ultimate object of my observations." This was the opening sentence of his paper of I8II, and as he had said much the same in the concluding words of his first paper (of $x 784$ ) on that subject, we see how faithful he remained to the plan of work he had adopted early in his scientific career. 
Speculations on the construction of the universe had been made before Herschel's time : by Thomas Wright in $175^{\circ}$, by an anonymous writer in 1755 (who afterwards turned out to be Immanuel Kant, and adopted most of Wright's conclusions), by Lambert, and by Michell. None of these writers had made any observations on which to found their theories. But Herschel would build on observed facts so far as possible. He began by attempting to find the distance of the fixed stars by measuring double stars. This turned out to be impossible; but the work done was not wasted, as hundreds of double stars had been found and measured. When many of these measures were repeated some twenty years later, the great discovery was made that not a few of these pairs of stars were revolving round their common centre of gravity. The nebulæ and clusters of stars were next systematically searched for; 2500 were found and their places determined. Herschel started with the idea that all nebulæ were composed of stars, and he therefore included clusters, even rather scattered ones, in his observations, as representing with dense clusters and nebulæ the different stages of the same class of bodies. But the discovery of some indubitably nebulous stars, or stars with atmospheres, made him recognise that there must be here and there in space some kind of "shining fluid " of which diffused nebulæ and planetary nebulæ were formed. This idea found very little favour among astronomers for many years, particularly after the completion of Lord Rosse's 6 -foot reflector, the maker of which was inclined to think every nebula "resolvable." Yet Herschel was found to be right when Huggins proved many nebula to have a gaseous spectrum.

Another discovery of Herschel's, which was doubted or denied until confirmed elsewhere, was the proper motion of the sun through space. Here there was perhaps some excuse for the doubters, as the material available for the investigation was rather scanty.

In order to get some idea of the distribution of the stars Herschel for some years took observations of the star-density in various parts of the sky by counting the stars seen in the field of his telescope. Making two assumptions - that his telescope could reach the boundaries of the Milky Way, and that the stars of the system were tolerably uniformly distributed-he was able to construct a rough diagram of the shape of the Milky Way system to which our sun belongs. This is the well-known disc or grindstone theory, according to which the stars are scattered between two planes, roughly parallel to the belt of the visible Milky Way, with a stratum running out to one side to represent the bifurcation from Cygnus to Scorpio. Near the centre of this system (also spoken of as "our nebula") Herschel placed our sun. In after years, in two papers of $18 \mathrm{I} 7$ and $\mathrm{x} 8 \mathrm{I} 8$, Herschel, as a result of his observations, was obliged to abandon the idea of uniform distribution, and also to recognise that his telescope could not reach the boundaries of the Milky Way system. But that the system extended very much further in the plane of the Milky Way than at righ angles to it, remained his opinion, though the conception of the system being a nebula- - that is, a star cluster - had been given up.

Here again there was, towards the end of the nineteenth century, a tendency to abandon Herschel's results, and the opinion was set forth in more than one quarter, that the Milky Way is really what it looks likea huge ring-shaped cluster. It has even been suggested that it is a gigantic spiral nebula inside which our sun is situated-at first sight a rather tempting proposal. But recent researches by Shapley have shown these hypotheses to be untenable; and his work on the distribution of globular clusters, showing the enormous distances of many thousands of light-years which separate them from us, agrees in a remarkable manner with the ideas worked out by the old astronomer at Slough exactly a hundred years earlier, in the last paper he sent to the Royal Society. J. L. E. D.

\section{Obituary.}

\section{Dr. Arthur Ransome, F.R.S.}

\section{THE} $E$ death of Dr. Ransome at Bournemouth in his eighty-ninth year recalls the memory of a Manchester physician who was a pioneer in the training of female health visitors, and in the investigation of tuberculosis and of the-cyclical waves of epidemic diseases. He died on July 25 ; and by a striking coincidence, at the first meeting earlier in the same day of Section I.- that of Preventive Medicine-of the Congress of the Royal Sanitary Institute then being held in Bournemouth, a message of appreciation of Dr. Ransome's past work had been authorised, which never reached him.

Dr. Ransome was born in Manchester in 1834. He became an honorary fellow of Gonville and Caius College, Cambridge, and for many years was consulting physician of the Manchester Hospital for Consumption, as well as Professor of Hygiene and Public Health at Owen's College, I880-95.

Dr. Ransome's chief writings related to tuberculosis; on which he published several books, as well as special contributions to the Epidemiological and other Societies. He gave the Milroy lectures to the Royal College of Physicians on the causes of phthisis, and received the Parkes Weber prize for special researches on tuberculosis. From his experiments he concluded that finely divided tuberculous matter is rapidly deprived of virulence in daylight and in free currents of air; that even in the dark, fresh air has some, though a retarded disinfecting influence, and that in the absence of currents of air the tubercle bacillus retains its infectivity for long periods of time. The general effect of his work was to emphasise the importance of disinfection of rooms occupied by tuberculous patients. At the same time Dr. Ransome attached greater importance to sanitary and social improvements in the prevention of tuberculosis than to direct attack on the bacillus.

In epidemiology Dr. Ransome was one of the first to investigate the influence of cyclical waves in producing the intermittent prevalence of epidemic diseases, apparently independent of the accumulation of unprotected persons. The Swedish tables of mortality, 